\title{
Pendampingan Penggunaan LaTeX untuk Penulisan Artikel Ilmiah bagi Dosen Universitas PGRI Palembang
}

\author{
Yusuf Hartono $^{1}$, Somakim ${ }^{2}$, Weni Dwi Pratiwi ${ }^{3}$, Jeri Araiku ${ }^{4 *}$, Zuli Nuraeni ${ }^{5}$ \\ 1,2,3,4,5 Universitas Sriwijaya, Palembang, Sumatera Selatan 30136, Indonesia \\ *e-mail korespondensi: jeriaraiku@fkip.unsri.ac.id
}

Pengiriman: 1 November 2019; Diterima: 21 November 2019; Publikasi: 28 November 2019

\begin{abstract}
Abstrak
Kegiatan pengabdian kepada masyarakat ini bertujuan untuk melatih dosen Universitas PGRI Palembang dalam menulis artikel ilmiah, membuat presentasi, dan persamaan matematika dengan menggunakan aplikasi LaTeX, serta mengetahui respon peserta pelatihan terhadap pelaksanaan kegiatan. Kegiatan ini dilakukan dengan menggunakan model pendampingan dengan metode pembagian alat dan bahan serta metode demonstrasi yang diikuti oleh 23 peserta dari berbagai fakultas. Respon peserta pelatihan sangat positif dengan range kepuasan untuk seluruh indicator berada pada kisaran $86 \%$ - 94\%. Respon tertinggi terdapat pada item mengenai pentingnya pelatihan, sedangkan item untuk efisiensi waktu pelaksanaan mendapatkan respon sebesar $86 \%$. Peserta pelatihan mengharapkan terdapat pelatihan bekelanjutan dengan waktu pelaksanaan yang lebih memadai.
\end{abstract}

Kata kunci: LaTeX; TeX; penulisan artikel ilmiah menggunakan LaTeX

\begin{abstract}
This community service activity aims to train lecturers of Universitas PGRI Palembang in writing scientific article, making presentation, and mathematics equations using LaTeX application, as well as understanding their responses toward the activity. This activity conducted employing assisting model with sharing tools, materials, and demonstration method, whereas 23 participants from different faculties joint the training. The response shows very positive satisfaction for all indicators with the range of $86 \%-94 \%$. The highest response is on the importance of the program, while time efficiency item scored $86 \%$. All participants wish for sustainable training with longer time period.
\end{abstract}

Keywords: LaTeX; TeX; scientific article writing using LaTeX

\section{Pendahuluan}

Salah satu poin Tridharma Perguruan Tinggi adalah melaksanakan penelitian dan mempublikasikan hasil pemikiran serta analisisnya tersebut. Kinerja jurusan, fakultas dan perguruan tinggi sangat dipengaruhi oleh seberapa luas dan berkualitasnya publikasi para dosen tetapnya. Merujuk Peraturan Menteri Pendayagunaan Aparatur Negara dan Reformasi Birokrasi (PAN RB), Nomor 17 Tahun 2013 (Kemenpanrb, 2013) dan Peraturan Menteri Pendidikan dan Kebudayaan Nomor 92 Tahun 2014 (Kemendikbud, 2014), kenaikan jenjang jabatan akademik dosen mewajibkan untuk publikasi pada jurnal ilmiah nasional terakreditasi dan jurnal internasional bereputasi di bidangnya. Kebijakan ini memberikan suatu arah agar publikasi ilmiah jabatan fungsional Dosen di Indonesia terus ditingkatkan. Adapun tujuan dari publikasi ini adalah mensosialisasikan hasil temuan dari kajian atau penelitian berdasarkan evidence (bukti/kebenaran/fakta/data) di lapangan baik di tingkat lokal, nasional, regional dan internasional(Darmalaksana \& Suryana, 2017). Lebih lanjut, pemerintah menargetkan bahwa peneliti di Indonesia akan memimpin jumlah publikasi ilmiah di Asia Tenggara pada tahun 2019 dengan 30.000 KTI (Kemenristekdikti, 2017). 
Dalam menulis ataupun mempresentasikan artikel ilmiah, mayoritas dosen di Universitas PGRI Palembang menggunakan Microsoft Office seperti Microsoft Office Word dan Microsoft Office Power Point. Namun dalam praktiknya, Microsoft Office memiliki kelemahan dalam proses pengerjaannya(Soffar, 2015). Sebagai contoh, Microsoft Office yang disarankan adalah yang original, di mana memerlukan biaya yang tidak sedikit, sehingga banyak pihak yang membajak aplikasi ini menggunakan crack. Microsoft Office juga membutuhkan update secara berkala, sehingga sangat mengganggu proses penulisan artikel karena seringnya pop-up muncul. Dari sisi editing, format Microsoft Word sangat sulit untuk beradaptasi, sebagai contoh format doc ke docx yang tidak kompatibel sehingga dapat mengubah format yaitu hilangnya spasi. File yang dihasilkan defaultnya berformat .docx dimana pada format ini tidak dapat dieksekusi atau dibaca oleh Microsoft Word 2003. Selain itu, saat mengupload tulisan ke web di mana susunan penulisan menjadi tidak rapi. Hal ini dapat menyebabkan penulis harus sering mengedit tulisan ataupun menyimpan tulisan dalam banyak format. Sebagai contoh, beberapa dosen Universitas PGRI Palembang program studi pendidikan matematika menyatakan bahwa salah satu masalah dalam membuat buku ajar adalah bahwa beberapa kali halaman buku berubah atau tidak sesuai draft karena pada saat proses percetakan ukuran halaman berubah. Sedangkan apabila disimpan dalam format pdf, maka jika ukuran kertas diperkecil dari A4 menjadi A5, maka font tulisan juga menjadi lebih kecil.

Selain Microsoft Office, platform lain yang dapat membantu penulisan artikel ilmiah (ataupun bentuk tulisan lain) bagi para dosen adalah LaTeX. LaTeX adalah perangkat lunak open-source yang dapat membantu untuk menyiapkan dan menulis dokumen ilmiah dan teknis (Pakin, 2005). LaTeX memiliki beberapa keunggulan dibanding software sejenis lainnya seperti Microsoft Word. Pertama, LaTeX membolehkan pengguna untuk fokus pada kualitas konten dokumen ketimbang format dan hal detil lainnya seperti font dan warna tulisan (Talbot, 2004). Kedua, LaTeX juga memudahkan pengguna untuk mengatur sitasi dan bibliografi (Doob, 2005). Ketiga, perangkat lunak ini sangat robust untuk menangani dokumen yang kompleks dan besar (Talbot, 2004). ini diperjelas oleh Gambar 1. Keunggulan yang ke-empat dan terakhir, LaTeX merupakan perangkat lunak yang gratis.

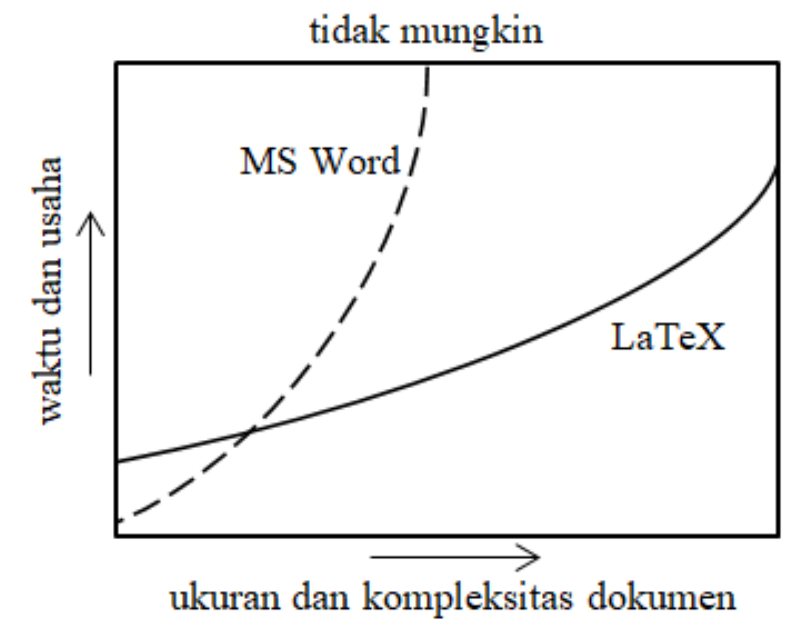

Gambar 1. Perbandingan MS Word dan LaTeX(Pinteric, 2018)

Namun disamping keunggulan tersebut, LaTeX menuntut pengguna untuk menggunakan sedikit bahasa pemrograman untuk memberikan instruksi. Oleh sebab itu, diperlukan pelatihan agar para peserta pelatihan minimal paham dasar-dasar dalam melakukan pemrograman dalam LaTeX. Oleh sebab itu, kegiatan PkM ini merupakan kegiatan awal untuk memperkenalkan program LaTeX kepada dosen Universitas PGRI Palembang. Berdasarkan uraian di atas, maka tujuan dari pengabdian ini adalah: (1) 
Melatih Dosen PGRI Palembang dalam menerapkan LaTeX untuk menulis artikel ilmiah, (2) mengetahui respon Dosen PGRI Palembang dalam penerapan LaTeX.

\section{Metode}

Khalayak sasaran dalam pengabdian ini adalah 20 dosen dari Universitas PGRI Palembang. Model pelaksanaan kegiatan pengabdian kepada masyarakat ini adalah model pendampingan untuk meningkatkan profesionalisme guru dalam penulisan artikel ilmiah, terutama dalam pelatihan menggunakan LaTeX, di mana diperlukan pemahaman mengenai bahasa pemrogramannya. Pendampingan ini bertujuan agar dosen peserta mendapatkan pengetahuan akan pilihan aplikasi yang dapat digunakan dalam menulis artikel ilmiah ataupun bahan ajar dan buku ajar. Pendampingan ini menggunakan metode pembagian alat (software LaTeX) dan bahan (modul penggunaan LaTeX) dan metode peragaan yaitu pendampingan secara mandiri dan kelompok kepada dosen peserta. Secara umum, kegiatan yang dilakukan adalah sebagai berikut: (1) Membuat modul penggunaan LaTeX untuk penulisan artikel ilmiah maupun bahan ajar, (2) memberikan pendampingan penggunaan LaTeX untuk menulis artikel ilmiah, (3) menyusun angket respon mengenai aplikasi LaTeX dan manfaatnya serta kegiatan pendampingan yang dilaksanakan, mengumpulkan data dengan menggunakan angket tersebut dan menganalisis hasilnya.

\section{Hasil dan Pembahasan}

Pelaksanaan kegiatan pengabdian kepada masayarakat ini dimulai dari tahap persiapan pendampingan, yaitu melakukan kontak dengan pihak Universitas PGRI Palembang. Koordinasi dilakukan secara intens, mulai dari tanggal pasti pelaksanaan, persiapan ruangan dan alat-alat pendukung kegiatan, serta penentuan dosen perwakilan masing-masing fakultas yang akan mengikuti program pendampingan penggunaan LaTeX ini.Untuk kepentingan pelaksanaan kegiatan, tim menyusun modul pelatihan.

\section{Membuat Modul Penggunaan LaTeX}

Pada tahap ini, tim PkM membuat modul yang diberikan pada peserta pendampingan LaTeX.Modul pelatihan LaTeX yang disusun oleh tim digunakan sebagai panduan peserta, terutama dalam mengenal fungsi dari tiap-tiap coding yang disampaikan. Selain itu modul yang dibagikan kepada peserta berguna sebagai bahan latihan di rumah.Modul ini terbagi menjadi 3 bagian, yaitu pengenalan mengenai LaTeX yang terdiri atas, cara Menginstal LaTeX, dan pengenalan fungsi-fungsi dan simbol-simbol pada LaTeX, seperti kode untuk memulai dan mengakhiri, kode jenis dokumen yang akan dibuat,cara membuat tabel, cara membuat jarak antar baris dengan menggunakan double backslash $(\backslash \backslash)$, dan cara membuat persamaan matematika.

Dalam menyampaikan materi, narasumber juga menyiapkan presentasi dengan menggunakan salah satu fasilitas yang ada pada program LaTeX, yaitu beamer.Beamer merupakan salah satu fasilitas dalam LaTeX untuk membuat presentasi. Contoh tampilah beamer ditunjukan pada Gambar 2.

Pengabdian Dosen Program Studi PEndidikan MATEMatika

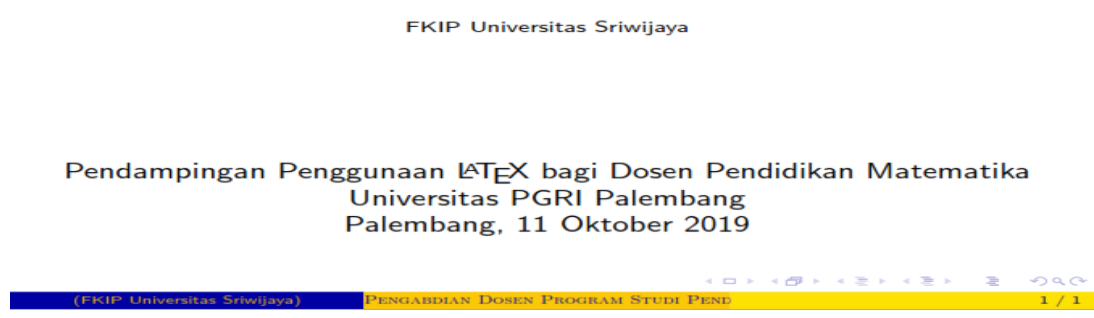

Gambar 2. Contoh presentasi dengan beamer 
JURNAL ANUGERAH. November 2019; I(1): 51 - 57

\section{Memberikan Pendampingan Penggunaan LaTeX}

Kegiatan pelatihan dilaksanakan di laboratorium matematika Universitas PGRI Palembang pada tanggal 11 Oktober 2019, dengan jumlah peserta sebanyak 23 orang. Terdapat 10 narasumber yang bertugas sebagai pemateri dan asisten dalam penggunaan LaTeX agar peserta dapat dengan mudah bertanya dan praktik langsung dalam penggunaan LaTeX.

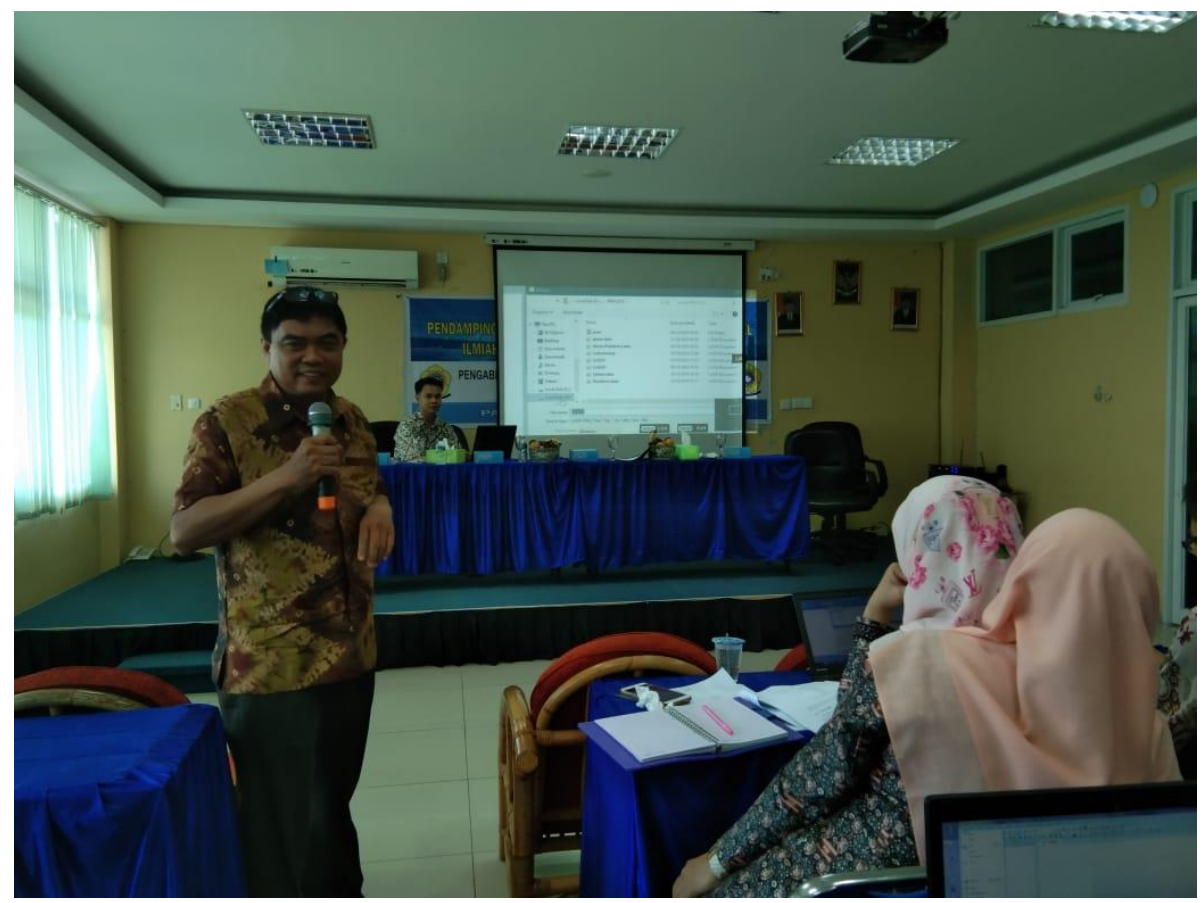

Gambar 3.Penyajian materi pengenalan LaTeX

Selama pelaksanaan, tidak terdapat gangguan yang signifikan. Pada saat pembuatan beamer, program tidak merespon dikarenakan resiptorybeamer kurang lengkap. Namun kendala ini bisa langsung diatasi oleh tim yang bertugas.

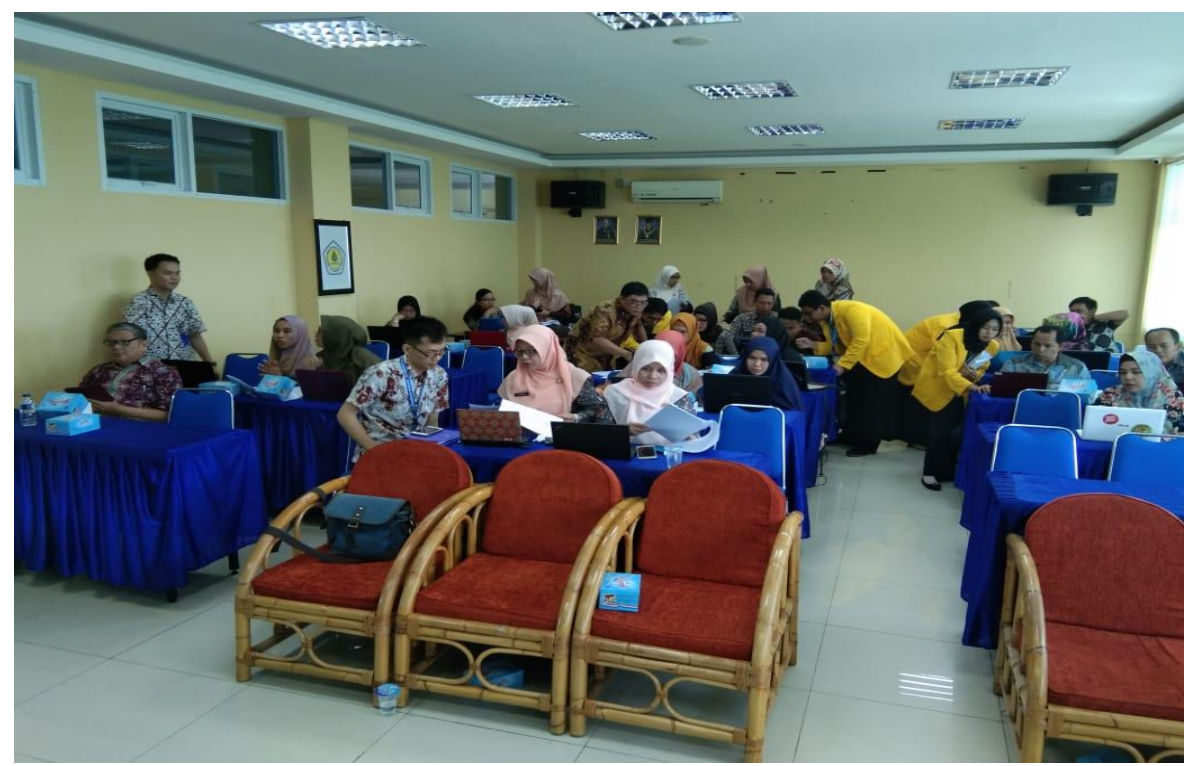

Gambar 4. Pendampingan penggunaan LaTeX 
Selain penyampaian materi, peserta juga diharuskan untuk membuat sendiri tulisan dengan menggunakan program LaTeX. Gambar 4 dan Gambar 5 adalah contoh kerja peserta pelatihan dengan format LaTeX dan outputnya dengan ekstensi .pdf.

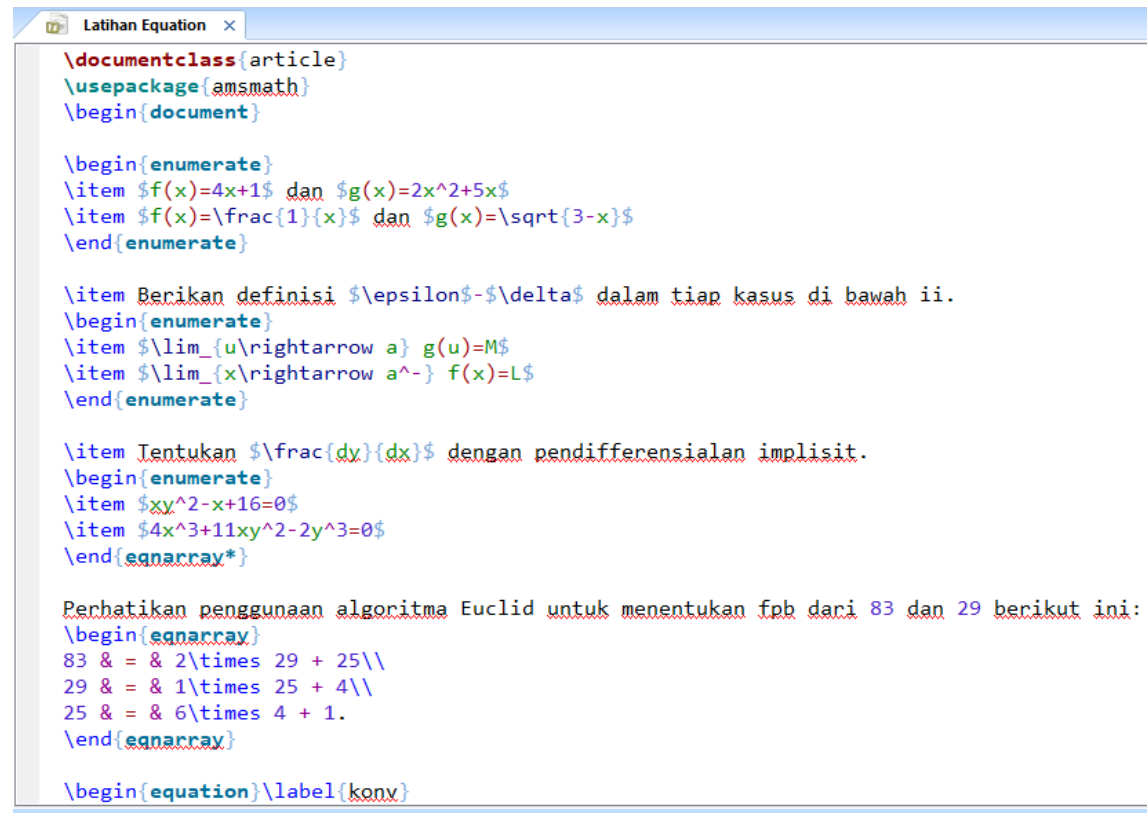

Gambar 5. Contoh hasil latihan peserta

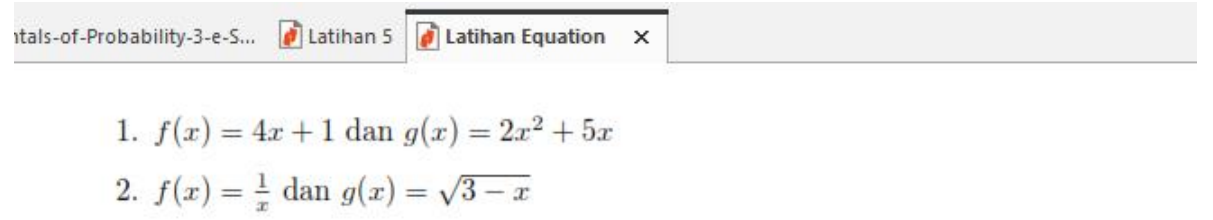

Berikan definisi $\epsilon-\delta$ dalam tiap kasus di bawah ii.

1. $\lim _{u \rightarrow a} g(u)=M$

2. $\lim _{x \rightarrow a^{-}} f(x)=L$

Tentukan $\frac{d y}{d x}$ dengan pendifferensialan implisit.

1. $x y^{2}-x+16=0$

2. $4 x^{3}+11 x y^{2}-2 y^{3}=0$

Perhatikan penggunaan algoritma Euclid untuk menentukan fpb dari 83 dan 29 berikut ini:

$$
\begin{gathered}
83=2 \times 29+25 \\
29=1 \times 25+4 \\
25=6 \times 4+1 . \\
A_{n} B_{n}=\left[q_{0} ; q_{1}, q_{2}, \ldots, q_{n}\right], n=1,2, .
\end{gathered}
$$

Gambar 6. Contoh output latihan peserta

\section{Mengumpulkan Data Respon Dosen}

Selain menyiapkan modul dan presentasi, tim PkM juga menyusun angket respon peserta mengenai kegunaan program LaTeX dan pelaksanaan kegiatan pelatihan. Angket respon peserta disusun dengan 
menggunakan program LaTeX yang terdiri atas 7 pernyataan. Pernyataan-pernyataan didiskusikan dengan seluruh anggota tim yang bertujuan untuk melihat respon peserta terhadap pentingnya materi pelatihan, kualitas modul yang dikembangkan, metode pendampingan, efektifitas waktu kegiatan, minat, serta keterlibatan seluruh peserta pelatihan.Sesaat sebelum penutupan, narasumber menyebarkan angket respon untuk peserta. Hasil dari respon peserta pelatihan LaTeX dapat dilihat pada Tabel 1.

Tabel 1.

Respon Peserta Pelatihan

\begin{tabular}{llc}
\hline No & \multicolumn{1}{c}{ Uraian } & Persentase \\
\hline 1 & Kegunaan Aplikasi LaTeX dengan kebutuhan peserta & $94 \%$ \\
\hline 2 & Kualitas modul tutorial penggunaan LaTeX yang digunakan & $89,6 \%$ \\
\hline 3 & Cara pendamping menyampaikan materi penggunaan LaTeX & $90,4 \%$ \\
\hline 4 & Efisiensi waktu kegiatan pendampingan LaTeX & $86 \%$ \\
\hline 5 & Keterlibatan peserta dalam proses penggunaan pendampingan LaTeX & $89,6 \%$ \\
\hline 6 & Minat peserta terhadap kegiatan & $92,2 \%$ \\
\hline 7 & Kepuasan kegiatan & $92,2 \%$ \\
\hline
\end{tabular}

Berdasarkan Tabel 1, dapat dilihat bahwa seluruh respon peserta positif. Respon tertinggi diperoleh pada item "Kegunaan Aplikasi LaTeX dengan kebutuhan peserta" yaitu 94\%. Peserta merasa bahwa walaupun awalnya mereka mengalami kendala dalam memahami bahasa pemrograman, namun setelah beberapa lama dipelajari, mereka memilih aplikasi LaTeX dibandingkan dengan Microsoft Word. Hal ini dikarenakan tampilan yang lebih elegan dan konsisten. Hal ini sejalan dengan temuan dari Knauff dan Nejasmic (2014) yang didasarkan pada rata-rata dan standar deviasi, menyatakan bahwa untuk formulasi matematis, kemampuan mengontrol teks, dan konsitensi, aplikasi LaTeX lebih baik dibandingkan Microsoft Word.

Respon terendah berada pada item "Efisiensi waktu kegiatan pendampingan LaTeX" yaitu sebesar $86 \%$. Hal ini dikarenakan peserta merasa waktu yang diberikan kurang memadai. Peserta masih ingin memperdalam kemampuan mereka dalam penggunaan LaTeX. Selain itu, waktu yang digunakan untuk memahami bahasa pemrograman juga tidak memadai (Knauff \& Nejasmic, 2014). Tim sangat mengapresiasi anstusiasme peserta ini. Oleh sebab itu, tim memberikan nomor kontak jika ada peserta yang ingin belajar lebih lanjut. Hal ini juga menjadi evaluasi bagi tim pengabdian untuk melaksanakan pelatihan dengan jangka waktu yang lebih panjang.

Beberapa hal yang perlu menjadi perhatian adalah: (1) Seluruh resiptory program harus diuji kelengkapannya untuk meminimalisir maslaah teknis di lapangan. (2) Kegiatan lanjutan perlu dilaksanakan dengan waktu yang lebih panjang sehingga pelatihan menjadi lebih mendalam.

\section{Kesimpulan}

Dari kegiatan yang telah dilakukan dapat disimpulkan bahwa peserta pendampingan sudah memahami dengan cukup baik dari segi pentingnya menguasai program LaTeX dan bagaimana mengoperasikan program tersebut. Hal ini dibuktikan dengan sebagian peserta sudah mampu membuat tulisan baik berupa artikel, presentasi dan penulisan persamaan matematis. Selain itu, respon peserta yang sangat baik. Hal ini ditunjukkan dengan hasil dari angket respon, dimana seluruh pernyataan mendapat nilai lebih dari 4. Peserta pelatihan juga antusias dalam pelaksanaan pelatihan di mana banyak dari peserta berpendapat bahwa waktu pelatihan untuk ditambah lagi atau dilakukan pendampingan lanjutan. 


\section{Saran}

Saran yang dapat diberikan adalah agar kegiatan ini dapat dilanjutkan dengan memberikan pendampingan secara berkala atau pendampingan lanjutan kepada dosen-dosen tersebut baik secara langsung (tatap muka) maupun online, sehingga masalah-masalah yang terindikasi saat melihat respon peserta pelatihan dapat teratasi dengan baik.

\section{Ucapan Terimakasih}

Ucapan terima kasih yang sebesar-besarnya kepada Universitas Sriwijaya yang telah menyetujui dan mendanai kegiatan Pengabdian Kepada Masyarakat ini. Pengabdian ini didanai oleh Hibah Iptek dan Seni Budaya Universitas Sriwijaya tahun 2019. Selain itu, kami juga mengucapkan terima kasih kepada seluruh dosen Universitas PGRI Palembang yang telah berpartisipasi dalam kegiatan pendampingan penggunaan LaTeX ini. Serta apresiasi sebesar-besarnya kepada seluruh mahasiswa yang terlibat sebagai panitia dan fasilitator pada kegiatan PkM ini.

\section{Referensi}

Darmalaksana, W., \& Suryana, Y. (2017). Korespondensi dalam publikasi ilmiah. Journal Perspective, 1(2), $1-8$.

Doob, M. (2005). A Gentle introduction to TeX: A manual for self-study. Canada: Manitoba University.

Kemendikbud. (2014). Peraturan Menteri Pendidikan dan Kebudayaan Republik Indonesia Nomor 92 Tahun 2014 Tentang Petunjuk Teknis Pelaksanaan Penilaian Angka Kredit Jabatan Fungsional Dosen. Jakarta: Kemendikbud.

Kemenpanrb. (2013). Peraturan Menteri Pendayagunaan Aparatur Negara dan Reformasi Birokrasi Nomor 17 Tahun 2013 Tentang Jabatan Fungsional Dosen dan Angka Kreditnya. Jakarta: Kemenpanrb.

Kemenristekdikti. (2017). Tahun 2019 Target Publikasi "Jurnal Internasional Bereputasi" Indonesia Mencapai 30 Ribu KTI. Diambil kembali dari https://risbang.ristekdikti.go.id/publikasi/beritamedia/tahun-2019-target-publikasi-jurnal-internasional-bereputasi-indonesia-mencapai-30-ribu-kti/

Knauff, M., \& Nejasmic, J. (2014). An efficiency comparison of document preparation systems used in academic research and development. PLOS ONE, 10(4), 1-12. doi:10.1371/journal.pone.0115069

Pakin, S. (2005). The comprehensive LaTeX symbol list. Comprehensive TeX archieve network. Diambil kembali dari http://tug.ctan.org/info/symbols/comprehensive/symbols-a4.pdf

Pinteric, M. (2018). Using LaTeX on Windows. Diambil kembali dari http://www.pinteric.com/miktex.html

Soffar, H. (2015). What are the advantages and disadvantages of Microsoft Word?. Diambil kembali dari https://www.online-sciences.com/technology/what-are-the-advantages-and-disadvantages-ofmicrosoft-word/

Talbot, N. (2004). Creating a PDF Document Using PDFLaTeX. Diambil kembali dari https://www.dickimaw-books.com/latex/pdfdoc/pdfdoc-a4.pdf

Talbot, N. (2004). LaTeX for complete novice. Diambil kembali dari http://www.dickimawbooks.com/latex/novices/novices-report.pdf 